\title{
Fracture Risk Assessment and How to Implement a Fracture Liaison Service
}

\author{
Nicholas R. Fuggle, M. Kassim Javaid, Masaki Fujita, \\ Philippe Halbout, Bess Dawson-Hughes, Rene Rizzoli, \\ Jean-Yves Reginster, John A. Kanis, Cyrus Cooper, \\ and on behalf of the IOF Capture the Fracture Steering \\ Committee
}

This chapter is a component of Part 4: Pillar III.

For an explanation of the grouping of chapters in this book, please see Chapter 1: 'The multidisciplinary approach to fragility fractures around the world—an overview'.

on behalf of the IOF Capture the Fracture Steering Committee

N. R. Fuggle · C. Cooper $(\bowtie)$

MRC Lifecourse Epidemiology Unit, University of Southampton, Southampton, UK

e-mail: nrf@mrc.soton.ac.uk; cc@mrc.soton.ac.uk

M. Kassim Javaid

Nuffield Department of Orthopaedics, Rheumatology and Musculoskeletal Sciences,

University of Oxford, Oxford, UK

e-mail: kassim.javaid@ndorms.ox.ac.uk

M. Fujita $\cdot$ P. Halbout

International Osteoporosis Foundation, Geneva, Switzerland

e-mail: mfujita@iofbonehealth.org; phalbout@iofbonehealth.org

B. Dawson-Hughes

Bone Metabolism Laboratory, Jean Mayer USDA Human Nutrition Research Center on

Aging at Tufts University, Boston, MA, USA

e-mail: bess.dawson-hughes@tufts.edu

R. Rizzoli

Division of Bone Diseases, Geneva University Hospitals and Faculty of Medicine,

Geneva, Switzerland

e-mail: Rene.Rizzoli@unige.ch

J.-Y. Reginster

Department of Public Health, Epidemiology, and Health Economics, University of Liège,

Liège, Belgium

e-mail: jyreginster@ulg.ac.be

\section{J. A. Kanis}

Centre for Metabolic Bone Diseases, University of Sheffield Medical School, Sheffield, UK

e-mail: w.j.pontefract@ shef.ac.uk 


\subsection{Introduction}

The fragility fracture epidemic is considerable, affecting one in three women and one in five men over the age of 50 years in the Western world [1-3]. This has significant cost to the individual (in terms of morbidity and mortality) but also accrues significant financial costs to the global health economy. Indeed, the annual cost of fragility fractures exceeded $€ 37$ billion in Europe (in 2010) [4] and \$20 billion in the United States (in 1992) [5]. With the substantial burden of osteoporosis set to rise, the magnitude of this problem can only get larger.

In order to countermand the incidence of fragility fractures two main approaches are required. The first is to ensure that those with osteoporosis are adequately treated, but the second, on which we focus in this chapter, is the timely and effective identification of those at risk of fragility fractures [6].

The index fragility fracture is a vital signal to indicate the need to assess and treat osteoporosis the commencement, or at least consideration, of treatment. Despite this a large proportion of patients presenting to healthcare professionals remain needlessly at risk and untreated [4, 7] in a so-called 'Treatment Gap' [8], with estimates suggesting that a mere $20 \%$ of fractured patients are assessed and treated appropriately (though this figure varies according to country and fracture site [9]). As a result, national and international clinical guidelines [10-12] and systematic reviews from the academic community $[13,14]$ recommend the use of a Fracture Liaison Service (FLS) in order to effectively close this treatment gap. It is also vital to establish an individual's risk of fracture and use this parameter to determine a suitable management plan.

\subsection{Fracture Risk Prediction}

In 1994, the World Health Organization produced an operational definition of osteoporosis as a bone mineral density (BMD) T-score of -2.5 or lower [15] and this has subsequently become the diagnostic criterion. Indeed, there is a 1.5-2.5 fold increase in fracture risk with each standard deviation decrease in BMD [16], however, the sensitivity of BMD alone to identify those at risk of fracture is less than $50 \%[17,18]$ and many patients sustain fractures with a $\mathrm{T}$ score higher than -2.5 . For this reason, fracture prediction tools have been developed to aid in the identification of 'at risk' individuals.

The Fracture Risk Assessment Tool (FRAX) was developed via systematic metaanalysis of primary data from 9 geographically spread cohort studies and validated in a further 11 cohorts and was published in 2008 [19]. Key principles were used to identify variables to be included in the FRAX algorithm including:

- The variable should be intuitively linked to fracture.

- The variable should be readily clinically available. 
- The variable should be (at least partly) independent of BMD.

- The variable should be associated with a risk which might be reversed by pharmacological therapy.

The clinical parameters chosen were age, sex, weight, height, previous fracture, parental hip fracture, current smoking, glucocorticoid usage, rheumatoid arthritis, secondary causes of osteoporosis, alcohol consumption and BMD (though this can be excluded in resource settings which preclude the measurement of BMD). The output is a 10-year probability of a major osteoporotic fracture (clinical spine, proximal humerus, distal forearm or hip fracture) and the 10-year probability of hip fracture. Fracture incidence varies geographically across the globe [20] and FRAX is calibrated to provide country-specific models [21].

These percentage risks can be used to inform therapeutic intervention thresholds. FRAX has been incorporated in more than 80 guidelines worldwide [21]. Examples include the guidance published by the National Osteoporosis Guidelines Group in the United Kingdom [22, 23], the National Osteoporosis Foundation (NOF) guidelines in the United States [24], The American College of Rheumatology (ACR) [25] and Scottish Intercollegiate Guidelines Network (SIGN) [26].

The Screening of Older women for the Prevention of fracture (SCOOP) trial aimed to establish the efficacy and cost-effectiveness of a community-based screening programme in primary care. A total of 12,483 women aged 70-85 years were recruited from general practice surgeries across the United Kingdom and randomised to either fracture screening using FRAX with dual X-ray absorptiometry as required or "standard care" (as a control). The primary outcome was the proportion of individuals sustaining fragility fractures in each group and secondary outcomes included; the proportions of all fractures, the hip fracture rate, cost-effectiveness, mortality and EQ-5D in each group and the qualitative evaluation of acceptability for the participants.

The findings of the study were published in 2018. Although there was no significant difference in the primary outcome of all osteoporosis-related fractures between the two groups $(p=0.178$, HR $0.94(0.85-1.03)$ or the rate of all clinical fractures $(p=0.83$, HR $0.94(0.86-1.03))$, the rate of hip fracture was significantly lower in the screening arm $(p=0.002$, HR $0.72(0.59-0.89))$ [27]. As shown in Fig. 14.1, the reduction in hip fracture risk was greater than $50 \%$ for those at highest risk of fracture [28]. Later health economic analyses demonstrated that screening in this way is cost-saving [29]. In conclusion the SCOOP study suggests that adopting this screening strategy in this population had the potential to cost-effectively prevent 8000 hip fractures per year.

The use of fracture prediction tools, together with BMD measures (if available) and a population screening strategy can all assist in identifying patients at risk of primary and secondary fracture. Of course, a further method to identify and treat 'at risk' individuals is via a Fracture Liaison Service (FLS). 


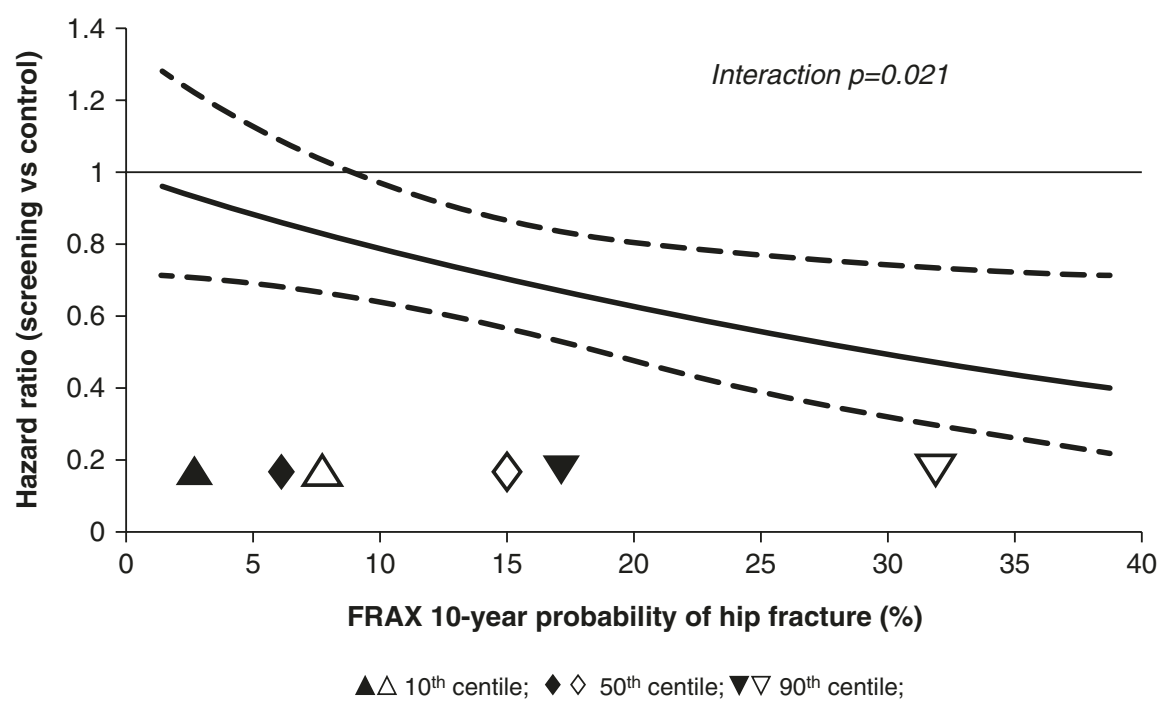

Fig. 14.1 Impact of the SCOOP screening strategy on hip fracture compared with usual care (control arm). The result is depicted as a hazard ratio, across range of FRAX 10-year hip fracture probabilities at baseline (calculated without BMD). There was an interaction of efficacy with baseline probability $(p=0.021)$. The symbols indicate the range of baseline probabilities in the whole study population (black symbols) and in the high-risk group identified by screening (white symbols) [28]

\subsection{Fracture Liaison Service}

\subsubsection{The FLS Model}

The FLS model is a coordinator-based, secondary fracture prevention service which is implemented by a healthcare system in order to ensure that those patients presenting with a fragility fracture are identified as osteoporotic and at risk of falls, and thus managed as such $[11,30,31]$ (Fig. 14.2). They serve two main purposes; one, to address the aforementioned problem of 'The Treatment Gap' and two, to improve communication between healthcare providers by providing a clearly defined pathway for patients with fragility fractures. It is composed of a team of healthcare professionals including an FLS champion (usually from internal medicine or orthopaedics) and a team of junior clinicians, nurses, allied health professionals and administrators.

Through the work of a dedicated 'case-finder' (usually a clinical nurse specialist) the service will aim to identify and assess fracture patients according to predetermined protocols in the geographic locality of the FLS and can be based in either primary or secondary care.

The model used in the United Kingdom is depicted in Fig. 14.3. 


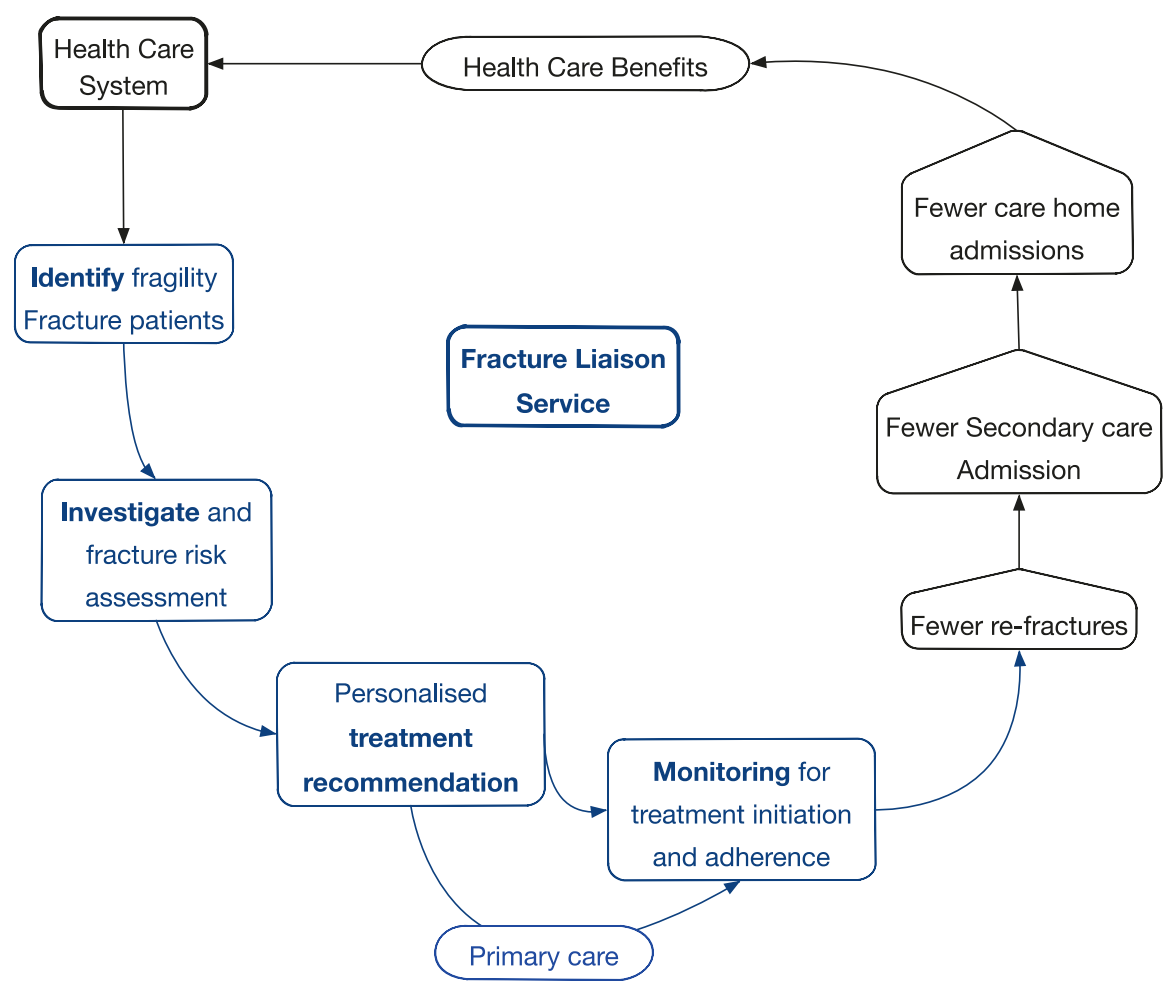

Fig. 14.2 Conceptual model of a Fracture Liaison Service

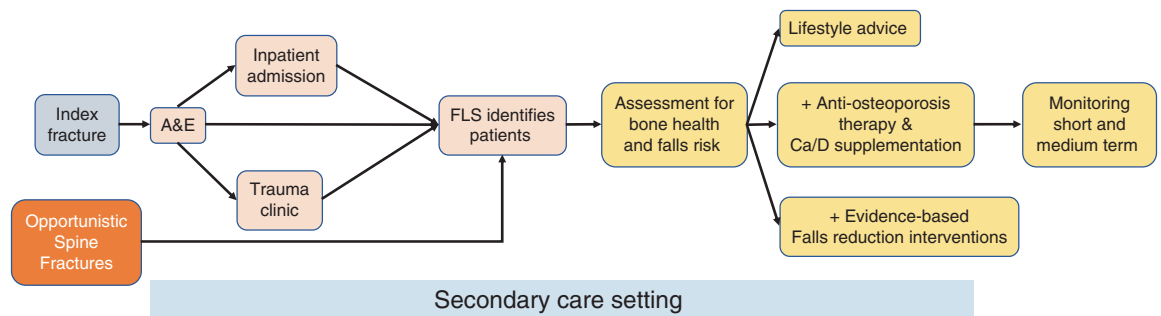

Primary care community setting

Fig. 14.3 An example of a Fracture Liaison Service model in the United Kingdom

\subsubsection{Evidence for Effectiveness of FLS}

In 2013, there were 57 FLS worldwide registered with the IOF Capture the Fracture ${ }^{\circledR}$ programme. In the same year, FLS coverage was assessed in 19 of 27 European countries. It was estimated that there was an FLS in less than $10 \%$ of their healthcare institutions [9]. The story was even more concerning in the Asia-Pacific region with 9 out of 16 countries reporting that none of their hospitals had an FLS [32] and 


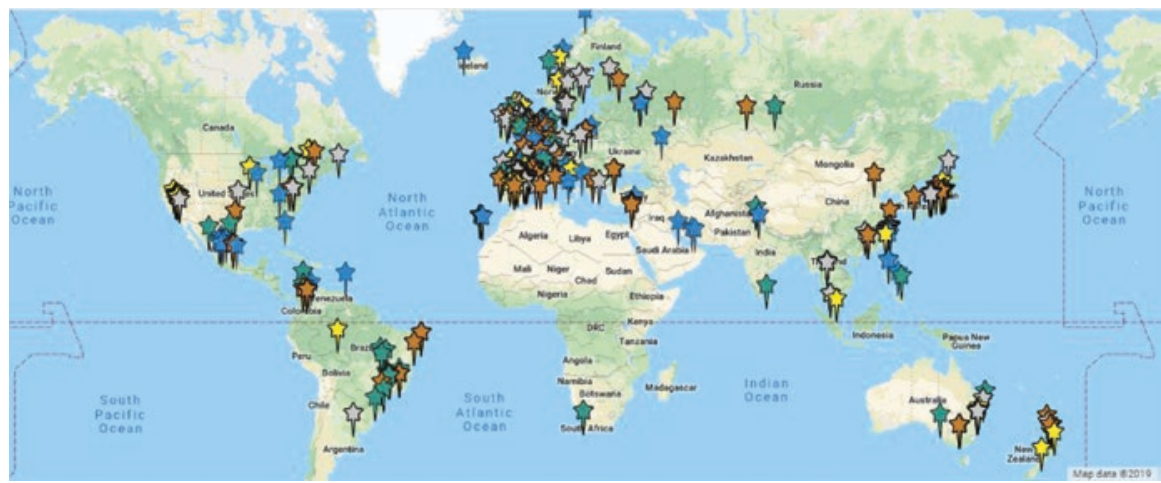

Fig. 14.4 The map of best practice recognises 327 FLS that identify over 345,000 patients every year in 41 countries

only Singapore reported an established FLS in over half their hospitals [33]. The International Osteoporosis Foundation (IOF) Capture the Fracture ${ }^{\circledR}$ (CTF) initiative has also allowed effective mapping of FLS across the globe (Fig. 14.4) and thus demonstrates an increase in uptake since the 2013 census. Indeed, in 2018 the total number of FLS had risen to 327 (identifying over 345,000 fracture patients/year) with 80 new FLS in that year alone, and three new countries registering their first FLS; The Philippines, Sri Lanka and Saudi Arabia.

Beyond coverage, it was previously considered difficult to compare interservice' efficacy and performance due to the wide range of service models in use [14], however, the CTF programme (launched in 2012) has drawn up standards against which services can be assessed. This 'Best Practice Framework' is an immense aid in comparing approaches and assessing the potential patient benefit. It identifies 13 criteria and standards including patient identification, patient evaluation, post-assessment timing, vertebral fracture identification, assessment guidelines, assessment of secondary causes of osteoporosis, falls prevention services, multifaceted nature of assessment, medication initiation, medication review, communication strategy, long-term management and database curation. Each of these standards is graded as bronze, silver or gold depending on the quality of the particular facet of the service. The FLS is then scored according to five domains composed of four different fracture types (hip, inpatient, outpatient and vertebral fractures) and an organisational domain (including falls assessment and database curation).

To engage the global medical community, CTF offers the Best Practice Recognition programme where FLS can submit their service to IOF for evaluation against the BPF standards in order to receive a gold, silver or bronze star. The FLS is showcased and plotted on the CTF Map of Best Practice that displays participating FLS in the programme and their respective achievement level (Fig. 14.4). To influence change, the map can be used as a visual representation of services which are available worldwide, their achievements, as well as the areas for improvement in secondary fracture prevention [34]. The map also serves as a policy advocacy tool that can be leveraged by healthcare professionals and clinics to reach out to policy makers in order to influence changes at national levels. 
Beyond the work by CTF, further analyses of the clinical and cost-effectiveness of FLS have been performed in recent years, including modelling within hypothetical cohorts.

Indeed McLellan and colleagues used a cost-effectiveness and budget-impact model (developed using 8 years of FLS data in a UK population) to show that, by implementing an FLS, 18 fractures could be prevented per year (for a hypothetical cohort of 1000 fragility fracture patients) providing an overall saving of $£ 21,000$ [35]. A similar study of a hypothetical cohort of 1000 patients in a Swedish population used a Markov micro simulation model to demonstrate that FLS implementation prevented 22 fractures with an incremental cost per QALY for FLS versus usual care of $€ 14,029$ [36].

In 2016, Hawley and colleagues examined the impact of FLS introduction or expansion on hip fracture outcomes in the United Kingdom using the Hospital Episode Statistics database. Their natural experiment included patients across 11 acute hospital trusts in England who had sustained a hip fracture between 2003 and 2013 and were aged more than 60 . Using time-series analyses, 30-day and 1-year mortality and second hip fracture were examined before and after the change in fracture prevention services. Of the 33,152 primary hip fractures included in the study, 1288 (4.2\%) went on to sustain a second hip fracture within 2 years, 3033 (9.5\%) patients died within 30 days of their primary hip fracture and 9662 (29.8\%) died within 1 year [37]. The introduction or expansion of a nurse-led fracture liaison service was protective for 30 day mortality (Hazard Ratio (HR) $0.80,95 \%$ CI $0.71-0.91$ ) and 1 year mortality (HR 0.84, 95\% CI 0.77-0.93) (Fig. 14.5) [37]. However, there was no effect on the occurrence of second hip fracture and no account of whether patients were actually seen by the FLS. A parallel qualitative study was undertaken for the sites and identified ensuring good adherence as key for service effectiveness [38]. The findings of this study provide substantial evidence that delegating monitoring and adherence to existing primary care services blunts the effectiveness of FLSs and supports the need to include monitoring, at least in the short to medium term, within the FLS specification.

The cost-effectiveness of FLS as an intervention for hip fracture was addressed in 2017 by Leal and colleagues who used Markov models to estimate the lifetime impact of an orthogeriatrician-led FLS, nurse-led FLS and usual care. They estimated that, for a female aged 83 years, an orthogeriatrician-led service was effective at $£ 22,709$ per QALY for all costs and $£ 12,860$ per QALY for healthcare costs. For males the cost-effectiveness of healthcare costs was $£ 14,525$ per QALY. These findings demonstrate that there is a significant economic rationale for the introduction of FLS. A more recent systematic review that included any study of FLSs irrespective of study design has also demonstrated the potential benefits from introduction of an FLS [39, 40].

The workforce impact and issues surrounding the running of an FLS were assessed in a qualitative analysis of interviews with 43 health professionals in the United Kingdom, all of whom had been involved in FLS [41]. Significant themes included communication, resourcing and adherence. It was felt that fracture prevention coordinators improved communication within the multi-disciplinary team, however, communication between secondary and primary care was sometimes a challenge. It was noted that the writing of a business case (a fundamental step en route to establishing an FLS in a hospital trust in the United Kingdom) was challenging and that there was under-resourcing of FLS in some sectors. Patient 
Fig. 14.5 Depicts the annual and quarterly regional mortality trends (for 30 days and 1 year) and second hip fracture (within 2 years) following initial hip fracture [37]

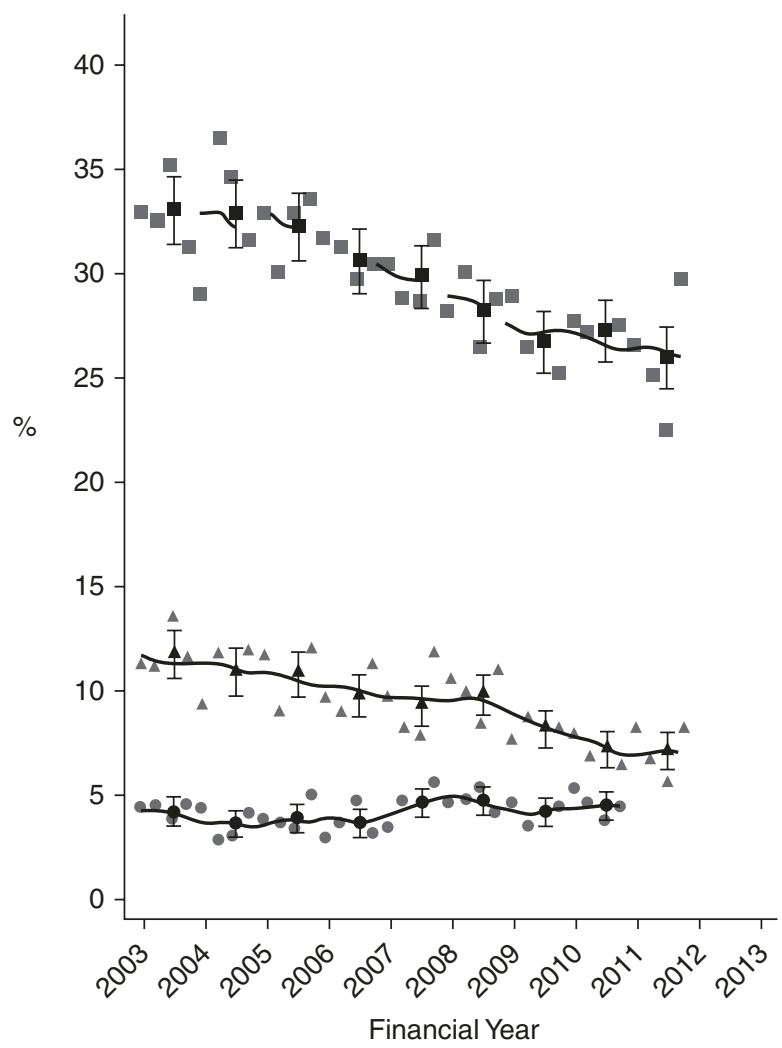

A Mortality within 30 days

- Mortality within 1 year

- Secondary hip fracture within 2 years

adherence to treatment was observed to be a weakness of the current FLS model and led to calls to improved medication monitoring.

In conclusion, an increasingly substantial body of research data supports the use of FLS by demonstrating a 50\% reduction in hip fracture mortality, a $20 \%$ reduction in secondary fracture and reduced drug therapy and cost in regions served by an FLS.

\subsection{How to Implement an FLS (a Step-by-Step Guide)}

The key stages in the development of an FLS are developing national prioritisation, the business case, implementation and sustainability. The first step is prioritisation for FLS at the policy level nationally or regionally. This involves a national coalition of professional societies, patient groups, existing FLS champions and relevant policy makers at the regional and national level. Central to the process of prioritisation is the data pack that links current and projected burden of fragility fracture with the 
patient, family, health care and societal benefits and includes a formal health economic evaluation.

A FLS business case is then developed that reflects the local benefits of FLS implementation as well as the local FLS costs and inter-dependencies. This may need to be informed by pilot studies to ascertain the optimal minimally disruptive pathway for patients through the different stages of identification, investigation, treatment recommendation and monitoring [42]. Effective patient engagement is key to ensure the pathway is patient centred.

Effective staged implementation of the FLS and scaling to become sustainable requires embedding quality improvement cycles into service provision. The improvement cycles should be supported by local, regional and national and peerpeer and peer-expert forums for discussion and sharing learning. Tools to deliver these programmes of work are being developed by the Capture the Fracture working group and include national prioritisation advocacy, FLS budget impact calculators and different methods for mentoring FLSs through implementation and sustainability of their services.

A coherent multi-disciplinary team should be identified and recruited, including a lead champion for osteoporosis, orthopaedic surgeon, physicians (likely to come from specialties including geriatrics, rheumatology or endocrinology), DXAspecialist radiologists, specialist nurses, physiotherapists and an FLS coordinator. The project team should also include representation from relevant stakeholders including pharmacy, primary care physicians, health system administration, patient champions, charity sector and the health system management funders. This team will provide a holistic overview and ensure that the FLS is structured to perform the functions required by all stakeholders. An initial audit should be performed in order to provide a 'pre-FLS' baseline for future analyses of quality improvement. The data collected should include the number of individuals aged $\geq 50$ years who attend with a hip fragility fracture, with a previous fragility fracture in the last 2 years, already receiving anti-osteoporosis medications and discharged on anti-osteoporosis medication. Additional information on length of stay, discharge destination, healthcare costs and extension to other fracture types will depend on the availability of contemporary national data.

\subsubsection{Benchmarking Your Service}

The processes of quality improvement described through 'Plan-Do-Study-Act' above only allow assessment of the service against itself; however, it has previously been identified that it would be helpful to compare the service to other FLS both nationally and internationally. The IOF has devised a Best Practice Framework for this purpose and FLS can register on the CTF website to be mapped and benchmarked. The 13 benchmarking criteria are graded as Level 1, 2 or 3 ( 3 being the best example of practice), as seen in Table 14.1 and include the following:

1. Patient identification - patients with fragility fractures may be identified (level $1)$, tracked through the health system and may be independently reviewed by the FLS (level 2 and 3). 
Table 14.1 The Capture the Fracture ${ }^{\circledR}$ Best Practice Framework for the international benchmarking of fracture liaison services

\begin{tabular}{|c|c|c|c|}
\hline BPF STANDARD & LEVEL 1 & LEVEL 2 & LEVEL 3 \\
\hline 1. Patient Identification & Patients ID'd, not tracked & Patients ID'd, are tracked & $\begin{array}{l}\text { Patients ID'd, tracked \& } \\
\text { Independent review }\end{array}$ \\
\hline 2. Patient Evaluation & $\mathbf{5 0} \%$ assessed & $70 \%$ assessed & $90 \%$ assessed \\
\hline $\begin{array}{l}\text { 3. Post Fracture Assessment } \\
\text { Timing }\end{array}$ & Within $13-16$ weeks & Within $9-12$ weeks & Within 8 weeks \\
\hline 4. Vertebral Fracture (VF) ID & Known VF assessed & Routinely assesses for VF & Radiologists identify VF \\
\hline 5. Assessment Guidelines & Local & Regional & National \\
\hline $\begin{array}{l}\text { 6. Secondary Causes of } \\
\text { Osteoporosis }\end{array}$ & $\mathbf{5 0} \%$ of patients screened & $70 \%$ of patients screened & $\mathbf{9 0} \%$ of patients screened \\
\hline 7. Falls Prevention Services & $\begin{array}{l}50 \% \text { of patients } \\
\text { evaluated }\end{array}$ & $\begin{array}{l}70 \% \text { of patients } \\
\text { evaluated }\end{array}$ & $\begin{array}{l}90 \% \text { of patients } \\
\text { evaluated }\end{array}$ \\
\hline 8. Multifaceted Assessment & $\mathbf{5 0} \%$ of patients screened & $70 \%$ of patients screened & $90 \%$ of patients screened \\
\hline 9. Medication Initiation & $\mathbf{5 0} \%$ of patients initiated & $\mathbf{7 0} \%$ of patients initiated & $\mathbf{9 0} \%$ of patients initiated \\
\hline 10. Medication Review & $\mathbf{5 0} \%$ assessed & $70 \%$ assessed & $90 \%$ assessed \\
\hline 11. Communication Strategy & Communicates to doctor & $\begin{array}{l}\text { Communicates to doctor } \\
\text { w/ } \% \mathbf{5 0} \text { criteria }\end{array}$ & $\begin{array}{l}\text { Communicates to doctor } \\
\text { w/ } \% 90 \text { criteria* }\end{array}$ \\
\hline 12. Long-term Management & 1 year follow-up & & $\begin{array}{l}6 \text { month follow-up \& } 1 \\
\text { year follow-up }\end{array}$ \\
\hline 13. Database & Local & Regional & National \\
\hline
\end{tabular}

*Criteria: FRAX, DXA, Vertebral DXA/X-ray, primary risk factors, secondary risk factors, falls risk, current medications, medication compliance, follow-up plan, lifestyle risk-factors, time since last fracture.

2. Patient evaluation-assesses the percentage of patients with a fragilty fracture who have been evaluated for the risk of future fracture via a clinical prediction tool $\left(\right.$ FRAX $\left.^{\circledR}\right)$ or assessment of bone mineral density.

3. Post-fracture assessment timing-assesses how quickly patients with fragility fractures are assessed with a formal fracture risk assessment by the FLS in weeks since the fracture.

4. Vertebral fracture identification-despite being the most common fragility fracture many vertebral fractures are identified by chance (e.g. as incidental findings in radiological investigations) due to variation in clinical presentation. To achieve the highest level of practice in this criterion it is necessary to liaise with radiology to ensure that they identify and report vertebral fractures and provide a coherent pathway for these patients to access the FLS.

5. Assessment guidelines - evaluates whether the practice of the FLS is aligned to local, national or international guidance for the assessment of fragility fractures.

6. Secondary causes of osteoporosis - assesses the percentage of patients with fragility fractures who are screened for secondary causes of osteoporosis.

7. Falls prevention services-concerns the percentage of patients evaluated for referral to a falls service.

8. Multifaceted assessment-addresses the assessment (and management) of lifestyle factors which may underlie the fracture.

9. Medication initiation-includes the percentage of patients who were eligible for treatment receiving anti-osteoporosis medication. 
10. Medication review-includes the percentage of patients who are on antiosteoporosis medication who have their compliance assessed and in whom alternative medications are considered.

11. Communication strategy - assesses the quality of communication between the FLS and doctors in primary and secondary care including whether the following items are communicated; FRAX ${ }^{\circledR}$ scores, DXA outcomes, vertebral imaging, primary and secondary risk factors for fracture, falls risk, current medication and compliance, follow-up plan, lifestyle risk-factors and time since last fracture.

12. Long-term management-assesses whether medication compliance and tolerance are assessed at 6 months and 1 year after commencement.

13. Database-refers to whether the FLS contributes to a database for fragility fractures at a local, regional or national level.

It should be noted that these criteria are similar to the data collected as part of national registries, including the Australian and New Zealand Hip Fracture Registry [43].

\subsubsection{Potential Barriers and How to Overcome them}

In some cases, the instigation of an FLS is hampered by barriers, both perceived and real, which can potentially be overcome.

Inadequate financial resources to afford an FLS nurse specialist is one such example with a potential solution being the employment (or re-deployment) of a member of secretarial staff to take on the administrative duties which form part of the FLS nurse specialist role. Language is a potential barrier to engaging with global resources (such as those available through CTF), however, the Best Practice Framework (BPF) document is currently available in 12 major languages: English, French, Spanish, German, Portuguese, Polish, Italian, Hebrew, Russian, Slovak, Chinese (both traditional and simplified forms) and Japanese. The BPF questionnaire (which is completed by all FLS joining the Capture the Fracture program) is now available in eight languages: English, Polish, Spanish, Portuguese, Japanese, Russian, German and Slovak. A Thai version is being developed in collaboration with local FLS experts and medical association in 2019.

Lack of prior experience in running an FLS can lead to a lack of confidence and halting of an FLS initiative. This can be addressed via educational tools and direct mentorship from experienced FLS providers.

As part of the CTF Educational Programme, webinars have been organised since 2015 with the aim to engage with the FLS community of CTF and provide relevant knowledge on FLS and secondary fracture prevention. The ongoing series of webinars provide an opportunity to learn from FLS experts who have established leading FLS across the globe and contributed to development of guidelines and policy on secondary fracture prevention. To this date, 27 webinars have been organised on topics ranging from how to get mapped on CTF; global success stories of FLS 
champions; the role of the FLS coordinator; fracture cascade and secondary fracture prevention; among many others. The webinars on how to get mapped on CTF have been conducted internationally in ten major languages (https://capturethefracture. org/webinars).

The CTF mentorship programme connects leading FLS experts with institutions willing to establish a new FLS. The programme creates the platform on which essential knowledge and skills can be exchanged by FLS champions with FLS in early stage of development, locally and regionally.

Since its inception in 2016, the mentorship programme has been running globally, offering a combination of both on-site training and FLS workshops to provide guidance on FLS implementation. On-site training has been conducted in France, Canada, Russia, Brazil, Argentina and United Kingdom; and FLS workshops in Russia, Mexico, Brazil, Argentina, Saudi Arabia and Australia. Interest has been growing especially in the Latin American, Middle East and Asia-Pacific regions.

The onsite training involves an FLS champion (mentor) hosting an FLS candidate (mentee) and training the candidate over the course of a day on the key steps of implementing an FLS and how to apply to CTF by submitting the BPF questionnaire. As the training follows a one-to-one scheme, the content is tailored to meet the precise needs of the mentee. On the other hand, FLS workshops involve a larger audience, often more than 15-20 FLS candidates within the same country. The four key steps of FLS implementation: (1) developing the policy case; (2) developing a business case; (3) how to implement and (4) how to make it sustainable are covered in 1 day. The workshops are organised in collaboration with a local patient or medical society that is a member of IOF and includes local experts in the panel. As with onsite training, the FLS workshops are customised to the health system of the country.

\subsubsection{Implementation in a Low-Resource Setting}

Fracture Liaison Services should seek to address the issue of fragility fractures within their given locality, and, of course, there will be variation in demographics of the patient group [44] and the healthcare resources available. However, the resources required to implement a FLS are actually fairly limited. The only technological components are a DXA scanner and a computer, and if neither of these is available then paper copies of the FRAX ${ }^{\circledR}$ tool are available for use in low-resource settings and treatment decisions can be made without bone mineral density data. In some areas, initiation of a single dose of zoledronate is triggered by the orthopaedic team in patients with hip fracture and normal laboratory results with calcium and vitamin D supplementation, reserving FLS for those patients with less severe fractures or abnormal laboratory findings [45]. The CTF mentorship scheme, described above provides expert support and advice to those setting up and FLS in a transitioning economy (though it should also be noted that a paucity of resources is not only a problem to transitioning economies). 


\subsection{Conclusions}

In conclusion, there is substantial evidence to demonstrate the clinical efficacy and cost-effectiveness of setting up a Fracture Liaison Service. In this chapter we have outlined a step-by-step guide for how to set up an FLS and benchmark it against other services internationally.

\section{References}

1. Melton LJ 3rd, Chrischilles EA, Cooper C, Lane AW, Riggs BL (1992) Perspective. How many women have osteoporosis? J Bone Miner Res 7(9):1005-1010. https://doi.org/10.1002/ jbmr.5650070902

2. Melton LJ 3rd, Atkinson EJ, O'Connor MK, O'Fallon WM, Riggs BL (1998) Bone density and fracture risk in men. J Bone Miner Res 13(12):1915-1923. https://doi.org/10.1359/ jbmr.1998.13.12.1915

3. Kanis JA, Johnell O, Oden A, Sembo I, Redlund-Johnell I, Dawson A, De Laet C, Jonsson B (2000) Long-term risk of osteoporotic fracture in Malmo. Osteoporos Int 11(8):669-674

4. Hernlund E, Svedbom A, Ivergard M, Compston J, Cooper C, Stenmark J, McCloskey EV, Jonsson B, Kanis JA (2013) Osteoporosis in the European Union: medical management, epidemiology and economic burden. A report prepared in collaboration with the International Osteoporosis Foundation (IOF) and the European Federation of Pharmaceutical Industry Associations (EFPIA). Arch Osteoporos 8:136. https://doi.org/10.1007/s11657-013-0136-1

5. Cummings SR, Melton LJ (2002) Epidemiology and outcomes of osteoporotic fractures. Lancet 359(9319):1761-1767. https://doi.org/10.1016/s0140-6736(02)08657-9

6. Kanis JA, McCloskey E, Branco J, Brandi ML, Dennison E, Devogelaer JP, Ferrari S, Kaufman JM, Papapoulos S, Reginster JY, Rizzoli R (2014) Goal-directed treatment of osteoporosis in Europe. Osteoporos Int 25(11):2533-2543. https://doi.org/10.1007/s00198-014-2787-1

7. Solomon DH, Johnston SS, Boytsov NN, McMorrow D, Lane JM, Krohn KD (2014) Osteoporosis medication use after hip fracture in U.S. patients between 2002 and 2011. J Bone Miner Res 29(9):1929-1937. https://doi.org/10.1002/jbmr.2202

8. Harvey NC, McCloskey EV, Mitchell PJ, Dawson-Hughes B, Pierroz DD, Reginster JY, Rizzoli R, Cooper C, Kanis JA (2017) Mind the (treatment) gap: a global perspective on current and future strategies for prevention of fragility fractures. Osteoporos Int 28(5):1507-1529. https://doi.org/10.1007/s00198-016-3894-y

9. Kanis JA, Borgstrom F, Compston J, Dreinhofer K, Nolte E, Jonsson L, Lems WF, McCloskey EV, Rizzoli R, Stenmark J (2013) SCOPE: a scorecard for osteoporosis in Europe. Arch Osteoporos 8:144. https://doi.org/10.1007/s11657-013-0144-1

10. Kanis JA, Cooper C, Rizzoli R, Reginster JY (2019) European guidance for the diagnosis and management of osteoporosis in postmenopausal women. Osteoporos Int 30(1):3-44. https:// doi.org/10.1007/s00198-018-4704-5

11. Eisman JA, Bogoch ER, Dell R, Harrington JT, McKinney RE Jr, McLellan A, Mitchell PJ, Silverman S, Singleton R, Siris E (2012) Making the first fracture the last fracture: ASBMR task force report on secondary fracture prevention. J Bone Miner Res 27(10):2039-2046. https://doi.org/10.1002/jbmr.1698

12. Marsh D, Akesson K, Beaton DE, Bogoch ER, Boonen S, Brandi ML, McLellan AR, Mitchell PJ, Sale JE, Wahl DA (2011) Coordinator-based systems for secondary prevention in fragility fracture patients. Osteoporos Int 22(7):2051-2065. https://doi.org/10.1007/s00198-011-1642-x

13. Ganda K, Puech M, Chen JS, Speerin R, Bleasel J, Center JR, Eisman JA, March L, Seibel MJ (2013) Models of care for the secondary prevention of osteoporotic fractures: a systematic review and meta-analysis. Osteoporos Int 24(2):393-406. https://doi.org/10.1007/ s00198-012-2090-y 
14. Sale JE, Beaton D, Posen J, Elliot-Gibson V, Bogoch E (2011) Systematic review on interventions to improve osteoporosis investigation and treatment in fragility fracture patients. Osteoporos Int 22(7):2067-2082. https://doi.org/10.1007/s00198-011-1544-y

15. Assessment of fracture risk and its application to screening for postmenopausal osteoporosis. Report of a WHO Study Group (1994). World Health Organ Tech Rep Ser 843:1-129

16. Roux C, Reginster JY, Fechtenbaum J, Kolta S, Sawicki A, Tulassay Z, Luisetto G, Padrino JM, Doyle D, Prince R, Fardellone P, Sorensen OH, Meunier PJ (2006) Vertebral fracture risk reduction with strontium ranelate in women with postmenopausal osteoporosis is independent of baseline risk factors. J Bone Miner Res 21(4):536-542. https://doi.org/10.1359/ jbmr.060101

17. Schuit SC, van der Klift M, Weel AE, de Laet CE, Burger H, Seeman E, Hofman A, Uitterlinden AG, van Leeuwen JP, Pols HA (2004) Fracture incidence and association with bone mineral density in elderly men and women: the Rotterdam Study. Bone 34(1):195-202

18. Wainwright SA, Marshall LM, Ensrud KE, Cauley JA, Black DM, Hillier TA, Hochberg MC, Vogt MT, Orwoll ES (2005) Hip fracture in women without osteoporosis. J Clin Endocrinol Metab 90(5):2787-2793. https://doi.org/10.1210/jc.2004-1568

19. Kanis JA, McCloskey EV, Johansson H, Strom O, Borgstrom F, Oden A (2008) Case finding for the management of osteoporosis with FRAX - assessment and intervention thresholds for the UK. Osteoporos Int 19(10):1395-1408. https://doi.org/10.1007/s00198-008-0712-1

20. Kanis JA, Oden A, McCloskey EV, Johansson H, Wahl DA, Cooper C (2012) A systematic review of hip fracture incidence and probability of fracture worldwide. Osteoporos Int 23(9):2239-2256. https://doi.org/10.1007/s00198-012-1964-3

21. Kanis JA, Harvey NC, Cooper C, Johansson H, Oden A, McCloskey EV (2016) A systematic review of intervention thresholds based on FRAX : a report prepared for the National Osteoporosis Guideline Group and the International Osteoporosis Foundation. Arch Osteoporos 11(1):25. https://doi.org/10.1007/s11657-016-0278-z

22. Compston J, Cooper A, Cooper C, Gittoes N, Gregson C, Harvey N, Hope S, Kanis JA, McCloskey EV, Poole KES, Reid DM, Selby P, Thompson F, Thurston A, Vine N (2017) UK clinical guideline for the prevention and treatment of osteoporosis. Arch Osteoporos 12(1):43. https://doi.org/10.1007/s11657-017-0324-5

23. McCloskey EV, Johansson H, Harvey NC, Compston J, Kanis JA (2017) Access to fracture risk assessment by FRAX and linked National Osteoporosis Guideline Group (NOGG) guidance in the UK-an analysis of anonymous website activity. Osteoporos Int 28(1):71-76. https://doi. org/10.1007/s00198-016-3696-2

24. Cosman F, de Beur SJ, LeBoff MS, Lewiecki EM, Tanner B, Randall S, Lindsay R (2014) Clinician's guide to prevention and treatment of osteoporosis. Osteoporos Int 25(10):2359-2381. https://doi.org/10.1007/s00198-014-2794-2

25. Grossman JM, Gordon R, Ranganath VK, Deal C, Caplan L, Chen W, Curtis JR, Furst DE, McMahon M, Patkar NM, Volkmann E, Saag KG (2010) American College of Rheumatology 2010 recommendations for the prevention and treatment of glucocorticoid-induced osteoporosis. Arthritis Care Res (Hoboken) 62(11):1515-1526. https://doi.org/10.1002/acr.20295

26. Kanis JA, Compston J, Cooper C, Harvey NC, Johansson H, Oden A, McCloskey EV (2016) SIGN guidelines for Scotland: BMD versus FRAX versus QFracture. Calcif Tissue Int 98(5):417-425. https://doi.org/10.1007/s00223-015-0092-4

27. Shepstone L, Lenaghan E, Cooper C, Clarke S, Fong-Soe-Khioe R, Fordham R, Gittoes N, Harvey I, Harvey N, Heawood A, Holland R, Howe A, Kanis J, Marshall T, O'Neill T, Peters T, Redmond N, Torgerson D, Turner D, McCloskey E (2018) Screening in the community to reduce fractures in older women (SCOOP): a randomised controlled trial. Lancet 391(10122):741-747. https://doi.org/10.1016/s0140-6736(17)32640-5

28. McCloskey E, Johansson H, Harvey NC, Shepstone L, Lenaghan E, Fordham R, Harvey I, Howe A, Cooper C, Clarke S, Gittoes N, Heawood A, Holland R, Marshall T, O'Neill TW, Peters TJ, Redmond N, Torgerson D, Kanis JA (2018) Management of patients with high baseline hip fracture risk by FRAX reduces hip fractures-a post hoc analysis of the SCOOP study. J Bone Miner Res 33(6):1020-1026. https://doi.org/10.1002/jbmr.3411 
29. Söreskog EBF, Shepstone L, Clarke S, Cooper C, Harvey I, Harvey NC, Heawood A, Howe A, Johansson H, Marshall T, O'Neill TW, Peters T, Redmond N, Torgerson D, Turner D, McCloskey E, Kanis JA, the SCOOP study (2020) Long-term cost-effectiveness of screening for fracture risk in a UK primary care setting. Osteoporos Int. https://doi.org/10.1007/ s00198-020-05372-6

30. Akesson K, Marsh D, Mitchell PJ, McLellan AR, Stenmark J, Pierroz DD, Kyer C, Cooper C (2013) Capture the fracture: a best practice framework and global campaign to break the fragility fracture cycle. Osteoporos Int 24(8):2135-2152. https://doi.org/10.1007/s00198-013-2348-z

31. Mitchell PJ, Cooper C, Fujita M, Halbout P, Akesson K, Costa M, Dreinhofer KE, Marsh DR, Lee JK, Chan DD, Javaid MK (2019) Quality improvement initiatives in fragility fracture care and prevention. Curr Osteoporos Rep. https://doi.org/10.1007/s11914-019-00544-8

32. Mithal A, Bansal B, Kyer CS, Ebeling P (2014) The Asia-Pacific regional audit-epidemiology, costs, and burden of osteoporosis in India 2013: a report of international osteoporosis foundation. Indian J Endocrinol Metab 18(4):449-454. https://doi.org/10.4103/2230-8210.137485

33. Chandran M, Tan MZ, Cheen M, Tan SB, Leong M, Lau TC (2013) Secondary prevention of osteoporotic fractures--an "OPTIMAL" model of care from Singapore. Osteoporos Int 24(11):2809-2817. https://doi.org/10.1007/s00198-013-2368-8

34. Mitchell P, Åkesson K, Chandran M, Cooper C, Ganda K, Schneider M (2016) Implementation of models of care for secondary osteoporotic fracture prevention and orthogeriatric models of care for osteoporotic hip fracture. Best Pract Res Clin Rheumatol 30(3):536-558

35. McLellan AR, Wolowacz SE, Zimovetz EA, Beard SM, Lock S, McCrink L, Adekunle F, Roberts D (2011) Fracture liaison services for the evaluation and management of patients with osteoporotic fracture: a cost-effectiveness evaluation based on data collected over 8 years of service provision. Osteoporos Int 22(7):2083-2098. https://doi.org/10.1007/s00198-011-1534-0

36. Jonsson E, Borgström F, Ström C (2016) Cost effectiveness evaluation of fracture liaison services for the management of osteoporosis in Sweden. Value Health 19:A347-A766

37. Hawley S, Javaid MK, Prieto-Alhambra D, Lippett J, Sheard S, Arden NK, Cooper C, Judge A (2016) Clinical effectiveness of orthogeriatric and fracture liaison service models of care for hip fracture patients: population-based longitudinal study. Age Ageing 45(2):236-242. https:// doi.org/10.1093/ageing/afv204

38. Drew S, Judge A, Cooper C, Javaid MK, Farmer A, Gooberman-Hill R (2016) Secondary prevention of fractures after hip fracture: a qualitative study of effective service delivery. Osteoporos Int 27(5):1719-1727. https://doi.org/10.1007/s00198-015-3452-Z

39. Wu CH, Kao IJ, Hung WC, Lin SC, Liu HC, Hsieh MH, Bagga S, Achra M, Cheng TT, Yang RS (2018) Economic impact and cost-effectiveness of fracture liaison services: a systematic review of the literature. Osteoporos Int 29(6):1227-1242. https://doi.org/10.1007/ s00198-018-4411-2

40. Wu CH, Tu ST, Chang YF, Chan DC, Chien JT, Lin CH, Singh S, Dasari M, Chen JF, Tsai KS (2018) Fracture liaison services improve outcomes of patients with osteoporosis-related fractures: a systematic literature review and meta-analysis. Bone 111:92-100. https://doi. org/10.1016/j.bone.2018.03.018

41. Judge A, Javaid MK, Leal J, Hawley S, Drew S, Sheard S, Prieto-Alhambra D, GoobermanHill R, Lippett J, Farmer A, Arden N, Gray A, Goldacre M, Delmestri A, Cooper C (2016) Health services and delivery research. In: Models of care for the delivery of secondary fracture prevention after hip fracture: a health service cost, clinical outcomes and cost-effectiveness study within a region of England. NIHR Journals Library. Copyright (c) Queen's Printer and Controller of HMSO 2016. This work was produced by Judge et al. under the terms of a commissioning contract issued by the Secretary of State for Health. This issue may be freely reproduced for the purposes of private research and study and extracts (or indeed, the full report) may be included in professional journals provided that suitable acknowledgement is made and the reproduction is not associated with any form of advertising. Applications for commercial reproduction should be addressed to: NIHR Journals Library, National Institute for Health Research, Evaluation, Trials and Studies Coordinating Centre, Alpha House, University of Southampton Science Park, Southampton SO16 7NS, UK, Southampton (UK). https://doi. org/10.3310/hsdr04280 
42. May C, Montori VM, Mair FS (2009) We need minimally disruptive medicine. BMJ 339:b2803. https://doi.org/10.1136/bmj.b2803

43. Australian and New Zealand Hip Fracture Registry, annual report (2019)

44. Tsabasvi M, Davey S, Temu R (2017) Hip fracture pattern at a major Tanzanian referral hospital: focus on fragility hip fractures. Arch Osteoporos 12(1):47. https://doi.org/10.1007/ s11657-017-0338-z

45. Senay A, Delisle J, Giroux M, Laflamme GY, Leduc S, Malo M, Nguyen H, Ranger P, Fernandes JC (2016) The impact of a standardized order set for the management of non-hip fragility fractures in a Fracture Liaison Service. Osteoporos Int 27(12):3439-3447. https://doi. org/10.1007/s00198-016-3669-5

Open Access This book is licensed under the terms of the Creative Commons AttributionNonCommercial-NoDerivatives 4.0 International License (http://creativecommons.org/licenses/ by-nc-nd/4.0/), which permits any noncommercial use, sharing, distribution and reproduction in any medium or format, as long as you give appropriate credit to the original author(s) and the source, provide a link to the Creative Commons license and indicate if you modified the licensed material. You do not have permission under this license to share adapted material derived from this book or parts of it.

The images or other third party material in this book are included in the book's Creative Commons license, unless indicated otherwise in a credit line to the material. If material is not included in the book's Creative Commons license and your intended use is not permitted by statutory regulation or exceeds the permitted use, you will need to obtain permission directly from the copyright holder.

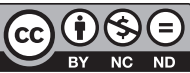

